Revista de Ensino em Artes, Moda e Design

Dossiê 6

A modelagem integrada ao projeto de Moda no âmbito do ensio

\title{
NEM TODO TRAJETO É RETO: LIMITES E POSSIBILIDADES PARA A SENSIBILIZAÇÃO DE ESTUDANTES DE DESIGN DE MODA POR MEIO DO ENSINO DE MODELAGEM
}

Not all path is straight: limits and possibilities for the sensibilization of fashion design students through pattern making teaching
Ni todos los caminos son rectos: límites y posibilidades para la sensibilización de los estudiantes de diseño de moda a través de la enseñanza de modelado

\author{
Bárbara Pavei Souza1
}

Adriana Cardoso Pereira²

\footnotetext{
${ }_{1}^{1}$ Professora do Centro Universitário para o Desenvolvimento do Alto Vale do Itajaí (UNIDAVI). Bacharel em Design de Moda pela Universidade do Estado de Santa Catarina (UDESC, 2013). Mestre em Ciências da Linguagem pela Universidade do Sul de Santa Catarina (UNISUL, 2017). Doutoranda em Ciências da Linguagem pela Universidade do Sul de Santa Catarina (UNISUL). Lattes: http://lattes.cnpq.br/2520899523874662. ORCID: http://orcid.org/0000-0003-4438-5363. Email: barbarapaveis@gmail.com.

2 Professora Colaboradora da Universidade do Estado de Santa Catarina (UDESC). Bacharel em Moda pela UDESC, 2010. Especialista em Docência no Ensino Superior pelo Centro Universitário Leonardo da Vinci (Uniasselvi, 2016). Mestranda da linha de Ensino em Artes Visuais pelo Programa de Pós Graduação em Artes Visuais (PPGAV/ UDESC). Lattes: http://lattes.cnpq.br/5811043302499373. ORCID: http://orcid.org/0000-0002-5814-474X. Email: drica.cp@gmail.com.
} 


\section{Resumo}

Este trabalho apresenta como escopo pensar o ensino de modelagem sob a luz da Pedagogia dos Saberes Sensiveis. Ao partir do reconhecimento de que as metodologias de ensino atuais são reflexo da lógica cartesiana de construção do conhecimento, objetiva-se explorar os limites e possibilidades vislumbrados no ensino e aprendizagem de modelagem do vestuário, visando sensibilizar os estudantes desta área para as tantas conexões que derivam do diálogo entre uma peça vestivel e o corpo humano. Mais especificamente, parte de relatos de experiência e inquietações das pesquisadoras como estudantes e docentes desta disciplina, bem como de revisão bibliográfica desta temática, para traçar o panorama do ensino de modelagem vivenciado, suas relações com o processo de ensino e aprendizagem e com a construção do conhecimento pelos profissionais de cursos superiores de Design de Moda. O estudo aponta a presença marcante do caráter instrucional nas práticas didático-pedagógicas da modelagem tradicional, reforçada pelas metodologias e materiais didáticos que se concentram no estabelecimento de ordens de execução e modelos pré-determinados. Por fim, esboçam-se alguns caminhos menos retilíneos para o ensino e aprendizagem deste componente curricular que pode ser encarado, no contexto educacional, não apenas como uma etapa do processo produtivo, mas também a partir da potencialidade em se constituir território de experimentação estética.

Palavras-chave: Modelagem do Vestuário; Ensino e aprendizagem; Saberes Sensíveis.

\section{Abstract}

This paper aims at presenting a scope of pattern making teaching under the notions of Sensible Knowledge Pedagogy. Taking into consideration that the principle of current teaching methodologies are a reflection of the Cartesian Logics of the knowledge construction, the aim of the present study is to explore the limits and possibilities of the teaching and learning process of pattern making, aiming at encouraging the students of the area to establish various connections that might arouse from the dialogue between a garment and the human body. More specifically, it starts from the reports and concerns of the researchers as students and teachers of this course, as well as the bibliographic reference of this theme, attempted to trace an overview on the pattern making teaching as an experience, its relationships with the teaching and learning process and with the knowledge construction by the professionals of the Fashion Design College Degree. The study points to the remarkable presence of the instructional character of the teaching practices in regards to the tradicional pattern making, enhanced by methodologies and instructional materials that concentrate on the establishment orders and pre-determined models. Finally, some paths are outlined less rectilinear for the teaching and knowledge of this subject that can be confronted, in an educational context, not only as a step for the productive process, 
but also from the capability of building a territory within esthetic experimentation.

Keywords: Pattern making; Teaching and learning process; Sensible Knowledge Pedagogy.

\section{Resumen}

El presente trabajo tiene como finalidad reflexionar sobre la enseñanza de modelado de vestuario en base a las ideas de las Pedagogias Sensibles. Teniendo en cuenta que las actuales metodologías de enseñanza son un reflejo de la lógica cartesiana en la construcción del conocimiento, el objetivo de este estudio es explorar los límites y posibilidades vislumbrados en la enseñanza y aprendizaje de modelado, con la intención de sensibilizar a los estudiantes de esta área hacia las múltiples conexiones que se derivan del diálogo entre una pieza de vestir y el cuerpo humano. Más especificamente, se parte de relatos de experiencias e inquietudes de las investigadoras como estudiantes y docentes de dicha disciplina, así como de la revisión bibliográfica de esta temática para trazar el panorama vivido en la enseñanza de modelado, sus relaciones con el proceso de enseñanza y aprendizaje, y con la construcción del conocimiento por parte de los profesionales de los cursos superiores de Diseño de Moda. El estudio muestra una notable presencia del carácter instructivo en las tradicionales prácticas didáctico-pedagógicas de modelado, reforzada por las metodologías y materiales didácticos que se concentran en el establecimiento de reglas de ejecución y modelos predeterminados. Por último, se esbozan algunos caminos menos rectilíneos para la enseñanza y aprendizaje de este componente curricular que se puede afrontar, en el contexto educativo, no solo como una etapa del proceso productivo, sino también desde el propio potencial de constituirse territorio de experimentación estética.

Palabras-clave: Modelado de Vestuario; Enseñanza y Aprendizaje; Pedagogías Sensibles.

\section{PONTUAÇõES INICIAIS}

A modelagem costuma ter cadeira cativa nos currículos de cursos superiores da área de Moda. Não por acaso. Ela é ferramenta fundamental para a construção dos produtos do vestuário e, portanto, recurso por meio do qual se promove a materialização do objeto vestível e dos sentidos que derivam da interação entre corpo e artefato.

Pode ser entendida tanto como o conjunto de traçados a partir dos quais o material têxtil é cortado para fins de confecção, quanto como a atividade que dá origem aos mesmos. Como prática, relaciona-se com um conjunto extenso de conhecimentos, técnicas, métodos, materiais e tradições que vêm se modificando ao longo dos anos conforme o contexto e o objetivo de sua utilização. 
Esta conexão direta entre as atividades produtivas da modelagem e da costura resulta na tendência de associar a modelagem à sua aplicação industrial. Contudo, levanta-se neste trabalho a hipótese de que é possível encará-la para além do repasse de um conjunto de regras e técnicas que trazem para o plano do palpável as ideias criadas anteriormente no papel. Especialmente por tratar, neste caso, do contexto de ensino superior voltado para o campo da criação. Por isso, levando-se em consideração que o exercício da modelagem demanda uma gama de habilidades perceptivas, interpretativas e de capacidade de manipulação de formas, essa prática pode ser vista também a partir da potencialidade inerente da modelagem em se constituir enquanto campo expressivo, criador de sentidos, ou seja, de experimentação estética.

Com isso não se pretende diminuir a importância da aplicação da modelagem sob o signo da produtividade. Seu mérito dentro desse contexto é indiscutível e a prática de modelar, nessa perspectiva, dialoga com conhecimentos construídos por meio de longos anos de aperfeiçoamento e dedicação de profissionais, docentes e pesquisadores sérios dessa área.

A perspectiva da modelagem como ferramenta para o desenvolvimento das capacidades criativas é ainda pouco trabalhada no ambiente acadêmico e dialoga, conforme se verá mais adiante, com pedagogias que despontam como alternativas ao modelo tradicional de ensino, como é o caso da Pedagogia dos Saberes Sensíveis, aporte teórico deste trabalho.

Assim, é objetivo do presente estudo abordar os limites e possibilidades presentes no ensino de modelagem para aproximá-lo de uma prática que dialogue mais estreitamente com a incerteza própria dos processos de criação. Trata-se de reflexões e propostas para o ensino e aprendizagem da modelagem que favoreçam o acesso a experiências da percepção e do saber, de experimentações estéticas em relação à produção de sentidos e de trajetos discursivos outros que não só os já instituídos no ensino tradicional de modelagem. De maneira mais específica, procura-se traçar o panorama e os paradigmas que norteiam o ensino de modelagem atualmente encontrados na realidade dos cursos superiores de Design de Moda; estabelecer paralelos entre a perspectiva educacional corrente, o perfil do egresso dessa área e a Pedagogia dos Saberes Sensíveis, de forma a identificar compatibilidades e dissonâncias entre elas. Por fim, de maneira propositiva e tomando as próprias vivências das pesquisadoras como ponto de partida, procurou-se esboçar algumas estratégias que permitem ampliar as possibilidades de sensibilização e reflexão dos estudantes por meio da modelagem.

O interesse na investigação da temática em questão surgiu, sobretudo, das inquietações das pesquisadoras em suas práticas docentes da disciplina de modelagem, bem como do contato com as propostas da abordagem pedagógica supracitada. A partir da compreensão de que houve expressiva alteração no contexto educacional desde que os primeiros referenciais para o ensino de modelagem foram sistematizados, entende-se que a pertinência dessa investigação introdutória se dê justamente no caráter reflexivo-propositivo em relação às estratégias empregadas para o ensino de modelagem em vista dos objetivos e perfis almejados para a formação dos sujeitos e futuros profissionais do campo da Moda.

Metodologicamente, este estudo utiliza-se tanto dos relatos de experiência das 
pesquisadoras como estudantes de Design de Moda e docentes da disciplina de modelagem em diferentes instituições de ensino superior, quanto de revisão bibliográfica sobre essa temática, para estabelecer o cenário de discussão que se segue.

\section{PANORAMA HISTÓRICO DO ENSINO DE MODELAGEM E SUA HERANÇA NOS CURSOS SUPERIORES DE DESIGN DE MODA}

Tradicionalmente, a prática da modelagem conecta-se tanto à origem da profissão dos alfaiates, quanto à atividade informal e cotidiana de desenvolvimento de trajes no ambiente familiar. Segundo Riffel (2003), as roupas eram a princípio confeccionadas em casa, por meio da criação de ovelhas ou cultivo do linho, tecelagem manual e posterior montagem das peças. Nesse contexto, a qualidade e o acabamento das roupas era bastante distante do que atualmente se conhece e sua confecção era bastante restrita.

Já no caso da alfaiataria, o trajeto aconteceu de maneira mais regulamentada, pois o conhecimento e domínio das técnicas de corte e confecção de peças do vestuário eram transmitidos aos familiares mais próximos ou aprendizes de confiança. De acordo com Riffel (2003), as oficinas de alfaiates se configuravam nos moldes das corporações de ofícios ${ }^{1}$, que se tornaram estruturadas e influentes (política e economicamente) em meados dos séculos XI e XII, contexto do desenvolvimento das cidades e do advento do comércio. Passos (2016), por sua vez, complementa com a informação de que é no período medieval que se estabelece o comércio de produtos manufaturados entre Oriente e Ocidente, sendo que "de todos os produtos em circulação, os produtos têxteis tinham maior presença no comércio" (PASSOS, 2016, p.14).

Ainda de acordo com Passos (2016), as corporações de ofícios eram conhecidas especialmente por sua hierarquia organizacional, composta por mestre, oficial e aprendiz. Em geral, os aprendizes não eram remunerados e trabalhavam por um longo período nas oficinas de alfaiataria para aprender com os mestres o ofício de corte e confecção de trajes. Muitas vezes, moravam na casa dos mestres.

Finalizads os anos como aprendizes, poderiam então tornar-se oficiais de alfaiate e abrir o próprio negócio, ou ainda seguir trabalhando com seus mestres por alguma remuneração. Comenta Riffel (2003) que, no entanto, o alcance do grau de mestre ficava limitado a aprendizes fora do eixo familiar dos mestres, pois além dos exames de maestria a que eram submetidos os aprendizes, havia uma série de exigências legais e morais presentes nos regulamentos desse ofício, "como o pagamento de direitos, o nascimento legítimo e a filiação à burguesia" (RIFFEL, 2003, p.13).

Alguns historiadores, como Laver (2005), registram mudanças no vestuário masculino e feminino em torno do século XIV, com diferenciações entre os sexos e presença de modelagem mais ajustada em relação ao corpo. É no contexto de Renascimento europeu que se tem registro de estudos geométricos do corpo e uma busca por certa padronização das técnicas de alfaiataria com vistas a melhorar seu resultado e agilizar sua execução. Data de 1589 o primeiro livro que se tem conheci-

\footnotetext{
${ }^{1}$ Caracterizadas como uma associação ou entidade formada por pessoas que exercem uma mesma atividade e obedecem a um rol de regulamentos que visavam evitar a concorrência e garantir um maior controle sobre o comércio. (RIFFEL, 2003; PASSOS, 2016).
} 
mento sobre técnicas de alfaiataria. Publicado em Madrid por Juan de Alcega, intitula-se Libro de Geometria, Pratica y Traça (BEDUSCHI, 2013).

Na sequência de publicações com vistas ao compartilhamento das informações relativas à alfaiataria, cita-se a obra Arte da Alfaiataria, de 1830, do alfaiate francês $\mathrm{H}$. Guglielmo Compaign. Na publicação podem ser encontradas as primeiras tabelas de medidas e o princípio do escalado que revolucionou a atividade de corte na Europa (RIFFEL, 2003).

O público atuante na atividade de alfaiataria era o masculino, pois apenas em 1675 foi permitido às mulheres trabalhar com costura e fundar suas próprias corporações (BELSCHANSKY, 2011). A partir dessa data, as modistas, que até então tinham o direito de confeccionar apenas a roupa íntima feminina, conquistaram o direito de executar todo tipo de vestuário feminino em suas oficinas. Segundo Riffel (2003), esse modelo se difunde pela Europa e põe fim a atuação exclusiva dos homens na atividade de corte e costura.

Embora houvesse, pontualmente, algumas publicações voltadas ao registro e repasse de técnicas de corte e costura, foi no ano de 1841 que o ensino na área de moda institucionalizou-se oficialmente. O francês Alexis Lavigne, mestre alfaiate da Rainha Eugênia, lançou os primeiros cursos para aprendizes de alfaiates pela École Guerre-Lavigne, em Paris. Após a morte de Alexis, sua filha, Alice Guerre, assume o negócio e o direciona ao público feminino (BELSCHANSKY, 2011; ESMOD, 2019), ampliando aos poucos seu rol de cursos e alcance.

A consolidação da noção de design, porém, ocorreria apenas na década de 1960, acabando por impactar a concepção do trabalho de costura e criação de moda. Nesse sentido, em 1976, a École Guerre-Lavigne passa a assumir o nome que carrega até hoje, École Supérieure des Arts et Techniques de la Mode (ESMOD). Com método de ensino patenteado, a escola conta atualmente com vinte unidades em treze diferentes países, incluindo o Brasil, e é ainda referência mundial no ensino desse campo do conhecimento, segundo Belschansky (2011) e o próprio site da instituição (ESMOD, 2016).

No Brasil, a prática da modelagem também apresentou relações com a alfaiataria e a atividade vinculada à produção caseira de vestuário, especialmente com o processo de migração de famílias de artesãos e camponeses europeus em meados do século XIX (RIFFEL, 2003). Contudo, a história da institucionalização do ensino de modelagem no país se aproxima mais do ensino tecnicista voltado à preparação de mão-de-obra para a indústria, ou seja, voltado às classes populares (BELSCHANSKY, 2011).

A demanda pelos produtos do vestuário foram crescendo por conta do aparecimento das primeiras fábricas de roupas no início do século $X X$, de maneira que os cursos profissionalizantes de corte e costura se proliferaram pelo país. Foi esse o período de abertura do Instituto Profissional Feminino, datado de 1911, no bairro do Brás, na cidade de São Paulo. A instituição dedicava-se ao ensino dos ofícios de corte e costura e à preparação para as funções doméstica. Também fundam-se, neste movimento, o Serviço Nacional de Aprendizagem Industrial (SENAI), aberto em 1942, e o Serviço Nacional de Aprendizagem Comercial (SENAC), em 1946 (BELSCHANSKY, 2011). 
Mesmo com os esforços no sentido de garantir a qualificação da mão-de-obra, Belschansky (2011) aponta que os profissionais que atuavam nessa área quando se deu o aquecimento da indústria da moda brasileira nas décadas de 1950 e 1960 eram praticamente autodidatas. Por falta de capacitação de profissionais, muitas empresas recorriam à cópia como garantia para a confecção das peças, comenta a autora. Como complementa, "essa classe, assim como as costureiras são até hoje, era limitada a aprendizado em cursos livres em instituições reconhecidas ou não, ou até mesmo a aprender em casa com mães, tias ou avós" (BELSCHANSKY, 2011, p. 69). Ainda conforme a autora, foi somente no ano de 1994, a partir de uma parceria entre a já citada ESMOD e o SENAC, que iniciou o funcionamento da primeira turma de Bacharelado em Design de Moda com Habilitação em Modelagem do Brasil, no ano de 1999 (BELSCHANSKY, 2011).

Portanto, a origem da prática de modelagem no Brasil transitou entre a informalidade de quem aprendeu a atividade através de manuais, com familiares ou mesmo por meio de tentativas e erros, e o ensino de caráter técnico e sistematizado, voltado à atuação nas indústrias. Pode-se dizer que as heranças marcantes do percurso trilhado pela área de modelagem no país ainda se fazem presentes em sala de aula na atualidade, mesmo em se tratando do contexto de cursos superiores de Design de Moda voltados à formação de profissionais para atuar nos setores criativos. A presença majoritária das mulheres nos cursos e a predominância de modelos para esse público nas obras sobre modelagem; a persistência de bibliografias de cunho instrucional, em que prevalecem os "comos" em detrimento dos "por quês", conforme apontam as pesquisas de lervolino (2014) e Belchansky (2011); a linguagem técnica e sucinta; bem como os métodos de realização da atividade assinalam algumas das marcas desse legado.

Em trecho retirado do prefácio do livro Modelagem Industrial Brasileira, referência nacional no estudo de modelagem e escrito por Duarte e Saggese em 2008, é possível captar o caráter tecnicista marcante no ensino de modelagem:

Passo a passo, decifra-se a gola xale, entende-se a blusa marinheira tão prezada por Gabrielle Chanel, ela mesma, uma mestra da modelagem, e é possível até ter sucesso no decote drapeado, que sempre dá a impressão de ser obra do acaso. Estes detalhes podem ter explicações sociológicas ou culturais, mas as páginas deste livro são mais objetivas. Aqui, tudo é cálculo e precisão [...] (DUARTE; SAGGESE, 2008, p. 7).

É compreensível, portanto, que a atividade de modelagem seja hegemonicamente atrelada a sua função industrial, técnica e de precisão, ou seja, voltados à prática do trabalho. ${ }^{2}$ Esse caráter garante o aumento contínuo da qualidade dos produtos e competitividade das indústrias têxteis e do vestuário brasileiros e não está, neste trabalho, sendo questionado. Aborda-se, sim, a ampliação do uso da atividade de modelagem para fins educacionais de outra natureza, no sentido de somar abor-

\footnotetext{
2 Em pesquisa, Silveira e Silva (2011) levantam informações quantitativas que comprovam esse apontamento no contexto de Santa Catarina. Segundo seu mapeamento, dos profissionais que atuavam naquele periodo nas empresas de vestuário do estado, 46\% haviam recebido formação de curso técnico, 29\% eram antigas costureiras e apenas 25\% provinham de formação superior. Quando o cenário é de grandes empresas, o número de modelistas formados em cursos técnicos sobe para $70 \%$, enquanto que no extremo oposto das microempresas, mais informais, o número de antigas costureiras lidera a atividade com $58 \%$.
} 
dagens ao invés de suprimir uma ou outra.

\subsection{Distintas dimensões da modelagem para o ensino superior}

Dentro do que se instaurou como cânone para o ensino de modelagem, tanto em cursos técnicos e tecnológicos quanto em bacharelados, costuma-se abordar o ensino desta atividade por meio de duas técnicas distintas: a modelagem plana, geométrica ou bidimensional, e a moulage, também chamada tridimensional ou draping ${ }^{3}$. As técnicas de modelagem hoje sistematizadas, plana ou moulage, podem ser desenvolvidas a partir de diferentes métodos, ou seja, há muitas formas de se executar uma base planificada ou de trabalhar o tecido sobre o busto.

Porém, pode-se notar que algumas características são intrínsecas a cada uma das técnicas. Assim, para fins de explanação sobre as particularidades de cada uma, este estudo utiliza a abordagem de Emídio (2018), que organiza as técnicas por meio de duas dimensões e finalidades, a saber: "1) técnica-criativa, voltada à concepção do vestuário; 2) técnica-produtiva, para a produção do vestuário [...]" (EMÍDIO, 2018, p. 62 , grifo da autora). Sobre essas dimensões, nos esclarece a autora que,

Enquanto na primeira se avalia as propriedades, comportamentos, caimentos e estruturas do tecido, considerando as demandas dos usuários quanto às questões sensoriais, ergonômicas, práticas e estética-simbólicas dos produtos, a segunda avalia as questões de viabilidade técnica-produtiva dos referidos materiais, ou seja, aspectos relacionados às questões de produção e reprodução dos produtos (EMÍDIO, 2018, p. 86).

Nas palavras de Emídio (2018), a dimensão técnica-criativa, conectada ao processo de criação, é contemplada pela moulage, pois carrega em si as naturezas técnica e criativa. Por isso, é identificada pela autora como um "recurso criativo, de experimentação e de estudo, e como meio de representação e de verificação das ideias geradas" (EMÍDIO, 2018, p. 63). Em contrapartida, à modelagem plana é conferida a dimensão técnica-produtiva, pois é a técnica predominante no meio produtivo e vincula-se à produção em série. Trata-se então de um recurso de produção industrial, "potencializadora no atendimento às funções práticas do produto junto ao usuário, bem como fundamental para a assertividade do processo de produção industrial dos produtos" (EMÍDIO, 2018, p. 63).

De fato, percebe-se que a origem das técnicas e sua aplicação acabam por impregná-las de sentidos e potencialidades distintas, porém complementares. Diante disso, cabe uma avaliação do emprego delas no contexto educacional, já que a abordagem didático-pedagógica direciona a lógica de produção de conhecimento.

Além disso, é importante tomar consciência das reais potencialidades de cada técnica, para que não se incorra na "supervalorização de um único instrumento, técnica ou método, em detrimento de outras possibilidades" (EMÍDIO, 2018, p. 62). Como pondera a autora, trata-se então de relacionar a técnica de modelagem aos objetivos, direcionamentos, contexto e aos fins almejados com o ensino.

3 Nos ambientes acadêmicos é mais recorrente que se utilize a nomenclatura em francês moulage, 


\section{TRAJETOS PESSOAIS E PROFISSIONAIS NA MODELAGEM}

As autoras iniciaram o contato com a produção de peças do vestuário em casa, ora acompanhando com curiosidade a mãe, que com sua Singer fazia pequenos consertos e peças simples, ora montando peças de roupas para bonecas com retalhos de tecidos.

Alguns anos mais tarde, mais especificamente em 2006 e 2009, iniciaram os estudos no curso de Moda. No início ficaram deslumbradas com tudo o que era proposto e tudo o que era "novo" e encantador naquele universo acadêmico. Mesmo iniciando os estudos em anos diferentes, aparentemente as coisas continuavam a funcionar da mesma forma.

Mal haviam experimentado desenvolver os primórdios de uma modelagem quando adentraram a sala reservada à prática dessa disciplina na universidade. Sem demora, as então acadêmicas receberam uma lista extensa e dispendiosa de materiais de modelagem e a indicação para realizar a cópia da apostila que guiaria a disciplina. Tudo parecia bastante preciso e técnico, mas instigante e desafiador ao mesmo tempo. As disciplinas de modelagem iniciavam pelo estudo da modelagem infantil e masculina, seguidas da introdução à modelagem feminina. Posteriormente, prosseguia-se para a modelagem feminina avançada, sendo um semestre para cada etapa.

Seguiram pela modelagem plana, cumprindo meticulosamente as ordens de execução, medidas, orientações de uso dos materiais, repetições dos exercícios em diferentes escalas para fixação do conteúdo, embora, na maioria das vezes, sequer compreendessem a lógica de tantas regras e medidas. Mas as autoras e estudantes à época tinham consciência de que os exercícios seriam cobrados tal qual constavam na apostila de modelagem e, por este motivo, os executavam à risca.

Até que no 60 semestre de curso as pesquisadoras entraram em contato com a técnica de moulage. Comumente, essa disciplina é trabalhada somente após algumas fases de modelagem plana, fato observado tanto no curso onde as autoras se graduaram, quanto nas instituições onde viriam a atuar como docentes anos mais tarde. A moulage faz o caminho inverso da modelagem plana, é um método utilizado para transformar a forma tridimensional em bidimensional, já que principia a construção das peças do vestuário com os tecidos diretamente sobre um manequim ou corpo humano. Considera-se a modelagem uma das etapas mais importantes na construção do vestuário. Para desenvolvê-la, são necessários cálculos de execução e conhecimentos sobre o corpo humano, como também conhecimentos sobre os aspectos ergonômicos que envolvem a construção e o equilíbrio do corpo e como o mesmo se "comportará" perante o caimento, as texturas e os volumes dos modelos propostos.

O método de trabalhar diretamente sobre o busto no desenvolvimento das peças é um dos recursos mais utilizados pelas autoras quando desenvolvem peças para alguns poucos clientes ou artigos para uso pessoal. Une-se a essa prática um pouco dos princípios de alfaiataria e, por vezes, porém mais pontualmente, a modelagem plana. Ou seja, recorre-se a esse processo de modelagem a maior parte das vezes que se deseja ou necessita criar.

Quando iniciaram o trabalho como docentes de modelagem, contudo, as pes- 
quisadoras se confrontaram com os mesmos métodos reprodutivistas com os quais tiveram contato enquanto estudantes. Assim, propunham exercícios seguindo as ordens de execução de que dispunham, algumas vezes por determinação dos materiais didáticos do local de trabalho, outras por hábito ou mesmo insegurança de principiantes.

Com o passar do tempo, puderam identificar, a partir da prática docente, as dificuldades para promover nos estudantes uma compreensão e uma visualização dos efeitos que o traçado geométrico sobre o papel ou no sistema CAD proporcionariam após a confecção daquela peça. As dificuldades talvez residam no fato de o ensino ser fracionado, pois em geral, costuma-se finalizar as atividades de modelagem para, em outra disciplina no semestre seguinte, realizar os testes das mesmas.

Sendo assim, a preocupação ainda existia em relação à dependência de ordens de execução, à forma mecânica como os conteúdos se davam com a aplicação das regras prontas, à reprodução de modelos pré-definidos que nem sempre condiziam com a realidade de consumo da região, além de padrões estéticos idealizados. Enfim, a ausência de diversidade de olhares sobre a prática da modelagem era uma realidade. Por outro lado, havia a necessidade da formação de caráter instrumental para o desempenho da função de modelista no contexto fabril, em especial porque ambas as autoras iniciaram suas carreiras enquanto docentes de cursos técnicos e tecnológicos na área do vestuário.

À medida que adquiriam mais confiança e experiências, as docentes começaram a inserir pontualmente informações adicionais, questionar certas regras e buscar, quando possivel, outras formas de provocar os estudantes para que compreendessem os sentidos e origens dos cânones utilizados no ensino da modelagem, bem como incentivá-los a percorrer outros caminhos. Foi com esta intenção que as linhas que seguem se desenrolam.

\section{NOVAS PERSPECTIVAS PARA A PRODUÇÃO DO CONHECIMENTO}

A inserção de novas ferramentas e tecnologias digitais, a ampliação do acesso à educação e as mudanças em relação ao compartilhamento e produção de informações apresentam-se como algumas das transformações em curso que tendem a impactar o ensino e os processos de produção de conhecimento de maneira significativa. Conforme Araújo (2014), após a terceira revolução educacional, cujo resultado foi a ampliação do acesso à escolarização e a conseguinte redução na qualidade da mesma, apresenta-se a necessidade de "reinvenção" da educação.

O modelo de escola e de universidade consolidado no século 19 tem agora, também, de dar conta das demandas e necessidades de uma sociedade democrática, inclusiva, permeada pelas diferenças e pautada no conhecimento inter, multi e transdisciplinar (ARAÚJO, 2014, p. 110).

Em consonância com o que aponta Araújo (2014), é importante salientar que não se trata de criar uma antagonia entre tradição e inovação. Garantir a conservação, a transmissão e o enriquecimento do conhecimento historicamente acumulado 
é uma das funções sociais da educação, uma vez que o novo necessita de alicerces sobre os quais possa ser erigido.

Para Araújo (2014), essas modificações serão sentidas, no âmbito educacional, por meio de três dimensões: nos conteúdos, na forma e nas relações entre professor e estudante ${ }^{4}$. Contudo, o cerne da renovação está alicerçada justamente sobre a terceira dimensão, ou seja, em torno do papel desempenhado pelos sujeitos envolvidos nos processos de ensino e aprendizagem. Assim, conforme ressalta o autor,

\begin{abstract}
A reinvenção das práticas educativas deve considerar um sujeito que constrói sua inteligência, sua identidade, e produz conhecimento por meio do diálogo estabelecido com seus pares, com professores e com a cultura, na própria realidade cotidiana com o mundo em que vive (ARAÚJO, 2014, p. 112).
\end{abstract}

Essa perspectiva aponta para o uso de metodologias ativas de aprendizagem, caracterizadas pela centralidade no estudante, autor do conhecimento, e o papel mediador do professor nesse processo. Fundamenta-se, portanto, no desenvolvimento da autonomia e da capacidade de "aprender a aprender" dos sujeitos.

É com o olhar voltado para a postura ativa e reflexiva do aluno, bem como para o papel fundamental do docente em conduzir o processo dialético de construção do conhecimento que as autoras Pimenta e Anastasiou (2014) empregam o termo ensinagem ${ }^{5}$. Segundo defendem, é preciso superar o processo tradicional de ensino, centrado na fala do professor e na memorização de conteúdos pelos alunos, já que “[...] a ação de ensinar não se limita à simples exposição dos conteúdos, mas inclui a necessidade de um resultado bem-sucedido daquilo que se pretendia fazer - no caso, ensinar" (PIMENTA; ANASTASIOU, 2014, p. 207, grifos das autoras). É por este motivo que, além de "o quê" e de "como", deve-se estimular a reflexão dos "por quês", ou seja, do pensamento autônomo.

A alteração do paradigma educacional vigente, ainda ancorado na visão moderna do conhecimento, também chamado cartesiano ${ }^{6}$ ou pensamento simplificante, depende do interesse e da ação conjunta dos atores envolvidos na educação. Essa prática tradicional de ensino, compartimentalizada, centrada no papel do professor, racionalizadora e ordenada nos é bastante familiar e é ainda predominante nos sistemas de ensino brasileiros.

A Pedagogia dos Saberes Sensíveis adentra o espaço do ensino como uma abordagem alternativa a essa lógica, cuja relação com o paradigma da complexidade, defendido pelo francês Edgar Morin, é direta. Também chamada de pedagogia dos afetos, a abordagem em questão encontra-se no limiar entre os campos da educação e da estética. Por esse motivo, centra-se na construção do saber por meio da experimentação estética, cuja relação com a percepção e a sensibilidade é indissociável. A

\footnotetext{
${ }^{4}$ Para maior detalhamento dessas dimensões, consulte Araújo (2014).

${ }^{5}$ Ensinagem, para Anastasiou (1998 apud PIMENTA; ANASTASIOU, 2014), é esse processo compartilhado de trabalhar os conhecimentos, no qual concorrem conteúdo, forma de ensinar e resultados mutuamente dependentes.

${ }^{6} \mathrm{O}$ pensamento cartesiano diz respeito ao "modelo de cientificidade que se constituiu a partir da revolução científica do século XVII e que lançou as bases da ciência moderna" (PÁTARO, 2008, p.19). Deriva do filósofo, matemático e físico francês René Descartes (1596-1650), considerado pai da filosofia moderna, e se caracteriza, grosso modo, pelo racionalismo aplicado ao método de investigação científica.
} 
relevância dessa linha pedagógica voltada para a formação da percepção acontece, como demarca Farina (2010, p.3), no fato de que "é a partir do que somos capazes ou não de perceber que produzimos conhecimento sobre nós mesmos e sobre o real." Portanto, origina-se de uma educação guiada pelo e para o sensível.

O presente trabalho encontra na abordagem da educação estética o seu aporte teórico, pois entende-se que está alinhada com as necessidades de formação dos estudantes para um ensino condizente com o que Morin chama de "educação na era planetária" (MORIN, 2007). Os alicerces dessa educação contemporânea são nítidos e desafiadores: "aprender a ser", "a fazer", "a viver juntos" e "a conhecer" (MORIN, 2005). É por esse motivo que se defende o desenvolvimento da sensibilidade no âmbito educacional, pois como acrescenta Arenhardt et al (2006, p. 6), é uma das tarefas do ensino preparar "sujeitos sensiveis e competentes para continuar se construindo, adquirindo autonomia e domínio do processo, fazendo aflorar do próprio olhar, uma sensibilidade de ser - estar no mundo".

\section{CAMINHOS POSSÍVEIS PARA UM ENSINO DE MODELAGEM PELO SENSÍVEL: PROPOSIÇÕES A PARTIR DO PERFIL PROFISSIONAL DO DESIGNER DE MODA}

Como fenômeno social, a moda encontra expressão pela busca e promoção do novo, alcançado por meio de recursos de criação diversificados. Sabe-se ainda que os processos que englobam a criatividade e a inovação são, por natureza, complexos e de caráter multidimensional. Isso porque demandam um grau elevado de interconexões, capacidade de análise, identificação de cenários e novas analogias para que ocorram.

Por esse motivo, o perfil dos sujeitos que atuam na área de modelagem se assenta de maneira direta sobre sua capacidade de criação do novo. Nesse caso, portanto, a presença da criatividade não é apenas desejada, mas fundamental para o desempenho das atividades ligadas à sua profissão.

Conforme o Projeto Pedagógico do curso de Bacharelado em Moda da Universidade do Estado de Santa Catarina (UDESC) ${ }^{7}$, são objetivos do curso promover a formação de profissionais que apresentem "criatividade e apropriação do pensamento reflexivo e da sensibilidade artística para projetar, planejar e desenvolver o produto de moda" (UDESC, 2016, p.11), de forma a interpretar e traduzir, por meio de suas criações, as necessidades de grupos sociais, indivíduos ou comunidade em relação "[...] aos problemas tecnológicos, socioeconômicos, gerenciais e organizativos, bem como a utilizar racionalmente os recursos disponíveis, além de conservar o equilíbrio do ambiente" (UDESC, 2016, p.7-8).

Essa perspectiva de formação na área de Moda demanda um olhar para a complexidade, de forma a contemplar os aspectos referentes ao processo produtivo em sua relação indissociável com o sistema social, político, econômico e ambiental nos quais está inserido.

\footnotetext{
${ }^{7}$ A escolha por pesquisar o PPC do curso de Moda da UDESC se deu pelo fato de que foi a instituição de formação das pesquisadoras, bem como é atualmente onde uma delas atua como docente. Acredita-se que assim seria mantida a coerência com os relatos e realidade de onde partem as reflexões deste trabalho.
} 
Conforme apontado anteriormente, sabe-se que a lógica que norteia a construção dos conhecimentos e sua legitimação acaba por definir as abordagens de ensino feitas em relação ao objeto de estudo. Desse modo, abaixo são esboçadas algumas proposições, tecidas a partir de reflexões sobre e para a prática docente das pesquisadoras em relação ao ensino de modelagem no contexto de cursos superiores de Moda ou Design de Moda. Nossa intenção centra-se no aprimoramento e aproximação da abordagem de ensino de modelagem com os princípios pedagógicos dos saberes sensíveis.

A) Primeiro a percepção, depois a abstração

Esta primeira proposição parte da premissa de que o processo de construção do conhecimento se origina com o desenvolvimento da percepção, e consequentemente, com a capacidade de nos tornarmos sensíveis ao objeto sobre o qual, posteriormente, teceremos reflexões racionalizadas. No caso da modelagem, sabe-se que a atividade inicia a partir do estudo do corpo. As bibliografias da área indicam esse tópico para o começo da disciplina, os estudiosos da modelagem e antropometria também. Porém, é costumeiro iniciar o ensino de modelagem por meio do traçado planificado das formas e volumes do corpo.

Defende-se aqui, no entanto, que a iniciação do aprendizado da modelagem seja por meio da moulage. Conforme definido anteriormente, esta técnica está mais conectada com os aspectos técnico-criativos do que a modelagem plana, que dificulta o processo de sensibilização do estudante para os volumes, movimentos do tecido e do corpo. Por conseguinte, torna complexa a compreensão das questões antropométricas, ergonômicas e estéticas que norteiam as regras empregadas na modelagem e que seriam mais facilmente compreendidas por meio da tridimensionalidade, característica da moulage.

Reconhecido por suas criações e cursos, o criador Jum Nakao desenvolve, há anos, oficinas de modelagem. Sua proposta assenta-se no entrelaçamento entre arte e moda, já que o profissional toma como princípio "a percepção da tridimensionalidade do corpo no espaço e suas infinitas possibilidades de vesti-lo a partir de uma visão escultórica e volumétrica" (JUM NAKAO, 2019, on-line). A abordagem didática de Jum Nakao apoia-se, portanto, na percepção primeira do corpo e se dá por meio da modelagem tridimensional. Assim, o criador parte dos princípios de espacialidade e, por meio da utilização de decalque corporal, propõe "compreender os princípios lógicos da modelagem para libertar a criatividade sobre novas formas de vestir. Sem cálculos e fórmulas" (JUM NAKAO, 2019, on-line).

Nessa perspectiva, acredita-se que o contato inicial da modelagem por meio da percepção - esta que se dá por meio do contato direto do sujeito com o objeto, e não por meios teóricos -, dos volumes e reentrâncias do corpo, das linhas de simetria e assimetria, dos mecanismos de articulação dos seus membros, abriria um caminho mais frutífero para a introdução aos estudos da modelagem. Dessa forma, os estudantes já estariam sensibilizados em relação ao corpo e seus volumes, suas particularidades e potencialidades quando enfim fossem apresentados aos conteúdos de modelagem plana, de caráter mais abstrato.

B) Tempos de diversidade

Este aspecto recai sobre a percepção de que os materiais didáticos de modela- 
gem do vestuário não contemplam traçados, interpretações ou estímulo ao desenvolvimento de modelos para diferentes tipos de corpos. Isso se estende, inclusive, para a modelagem tridimensional.

Como dito anteriormente, usualmente o ensino de modelagem concentra sua aplicação na prática do trabalho. Por esse motivo, seus conteúdos são desenvolvidos a partir da tabela de medidas, no intuito de agilizar e padronizar os resultados. $O$ corpo usado como base para o desenvolvimento das atividades de modelagem são, em geral, os corpos medianos - tamanho 42 para o feminino -, com medidas proporcionais entre si.

Tendo em vista as recentes discussões em relação aos padrões estéticos dominantes, cabe aqui apontar a necessidade de inserção de distintas concepções de corporeidade no ambiente acadêmico, de maneira a incentivar reflexões e contribuições para uma sociedade de respeito à diversidade. Onde estão contemplados o corpo obeso, o corpo idoso, o corpo com deficiência no ensino de modelagem? Isso sem adentrar o campo de discussão sobre gênero, temática que têm impactado sobremaneira no consumo de moda, e ainda está distante do contexto de ensino de modelagem.

Acredita-se, portanto, que a prática de pensar e modelar para diferentes biotipos e perfis possa ser inserida no ambiente de sala de aula, principalmente a partir do questionamento do padrão estético para o qual se costuma criar e do desejo ou não de reafirmação do mesmo por parte dos estudantes.

Além disso, cabe ainda questionar a escolha dos modelos de vestuário propostos pelos materiais didáticos de modelagem, cuja relação com os primórdios dessa atividade ainda se faz presente. Em análise realizada pelas autoras em três diferentes bibliografias de modelagem - apostilas de modelagem da UDESC (2017), Modelagem Industrial Brasileira, de Duarte e Saggese (2010) e Aprenda a costurar, de Brandão (1967) -, percebe-se a centralidade da figura feminina, público-alvo dos materiais de modelagem e costura por motivos que já foram anteriormente abordados. Percebe-se, igualmente, a permanência de formas, modelos e vestígios de uma subjetividade feminina ainda conectada aos valores relacionados ao decoro, à valorização de um corpo magro e jovem e ao seu papel na estrutura familiar patriarcal.

C) Nem todo trajeto é reto, nem o mar é regular

A reflexão desse item se debruça sobre o uso recorrente de ordens de execução no ensino de modelagem. Com presença marcante nas bibliografias da área, esse recurso reforça o caráter instrucional com que a temática é abordada. Em estudos voltados para o ensino de modelagem, lervolino (2014), Emídio (2018) e Belschansky (2011) destacam problemáticas atreladas ao ensino de modelagem por meio de ordens de execução.

Embora configurem um artifício importante para o registro e sistematização dos conhecimentos da área, as pesquisas apontaram que, além de problemas identificados na estruturação e comunicação eficaz, as ordens de execução, por si só, são insuficientes para promover o entendimento profundo dos conteúdos e das regras, bem como contribuem para o distanciamento de um processo autônomo e reflexivo de aprendizado. Conforme destaca Emídio (2018, p. 111), 
[...] ensinar modelagem no contexto de projetos de design de moda contemporâneos, não pode se resumir em demonstrar ao aluno as possibilidades de configurações previstas com base em regras rígidas e de forma arbitrária, ao contrário, deve-se levar o aluno a ampliar seu repertório de conhecimento e de domínio técnico-criativo e técnico-produtivo nesta área, para proposições inovadoras.

Acredita-se que a utilidade das ordens de execução possa residir na construção das bases para o exercício da modelagem plana. Trata-se da representação dos contornos do corpo por meio de traçados geométricos e são utilizados como ponto de partida para a interpretação de modelos. Do ponto de vista de sua aplicação em contextos onde se requer velocidade no trabalho, esse recurso é de grande valia. Contudo, do ponto de vista da construção do conhecimento pelo estudante, as ordens de execução não deixam muitas dúvidas de que apresentam limitações, como apontado pelas pesquisadoras.

Problemática maior se dá na aplicação de ordem de execução voltada para a interpretação de modelos. Nesse caso, a proposta em si é incoerente mesmo com a prática profissional do modelista em ambiente fabril, que dificilmente recorrerá a algum manual que indique em quantos centímetros deverá descer a partir do pescoço para que se tenha um decote "V". A interpretação é variável de acordo com o efeito que se deseje conferir a peça final. Portanto, pré determinar todos os procedimentos consistiria em encarar a atividade de modelagem como algo estanque. Além disso, pode-se promover nos estudantes a falsa ideia de que há uma única maneira de se realizar determinado modelo.

Em prática de sala de aula é possível perceber que esse recurso causa um processo automatizado de reprodução das ações propostas pelo material, muito embora possa haver esforços docentes ou interesse de discentes para contextualizar e compreender aquela informação. Esse método, como acrescenta Emídio (2018), não comporta o pensamento complexo necessário para a promoção de um aprendizado significativo e capaz de atuar frente aos problemas reais, tampouco estimula a aquisição de competências e habilidades que possibilitem ao sujeito aplicar os conhecimentos adquiridos em novos contextos ou ideias.

D) Interconexões, transversalidades

Partindo da contribuição de autores que se debruçaram sobre a temática do ensino inter e transdisciplinar, e tendo como paradigma a Pedagogia dos Saberes Sensíveis, despontam como estratégias possíveis para o alcance deste panorama o uso da Aprendizagem Baseada em Problemas (ABP), a Aprendizagem Baseada em Problemas e por Projetos (ABPP), ou ainda a metodologia da problematização, detalhados nos trabalhos de Araújo e Sastre (2016); Araújo (2014); e Pátaro (2008). As metodologias de ensino baseadas em problemas partem do princípio de centralidade do sujeito aprendente em contextualização direta com sua realidade, e contemplam diferentes estratégias para a sua execução: projetos integradores; temas transversais ou ainda temas centralizadores do processo de ensino e de aprendizagem.

Nos centros de ensino onde as autoras atuam como docentes, nota-se a presença de projetos interdisciplinares voltados à conexão de uma parcela das unidades curriculares de uma fase específica. Contudo, com exceção das atividades voltadas para a coleção de formatura, as disciplinas seguem independentes entre si, cada qual 
responsável por parte da orientação do projeto, que compete em espaço e tempo com os demais conteúdos do semestre.

De maneira geral, as experiências com projetos indicam resultados positivos no que diz respeito à participação, à autonomia, ao interesse e ao desenvolvimento de capacidades de resolução de problemas pelos estudantes. Apresenta-se, portanto, como um recurso valioso na busca de um processo de ensinagem efetivo.

\section{LIMITES E POSSIBILIDADES: POSSÍVEIS PONTOS DE PARTIDA}

Como inicialmente abordado, constava como objetivo deste estudo a investigação sobre as barreiras e potencialidades identificadas no ensino de modelagem em relação à sua capacidade de sensibilizar os estudantes, com vistas a promover uma aproximação da abordagem da Pedagogia dos Saberes Sensíveis.

Foi possível identificar que o ensino de modelagem ainda se conecta com o caráter instrumental, característico do contexto de surgimento do ensino da área no Brasil. Esse perfil tem dupla origem: a) a modelagem ensinada de maneira informal, por meio de cursos livres, por familiares que dominavam as técnicas ou através de manuais que promoviam a atividade do corte e costura, em geral, direcionada às muIheres e em sintonia com sua formação para os serviços domésticos; e b) a formação proveniente dos cursos técnicos, voltados para constituição de obra para a indústria e por meio dos quais o ensino de modelagem foi sistematizado e organizado formalmente.

Em qualquer uma das duas situações, é possível perceber características comuns: a presença da mulher como trabalhadora e público-alvo dessa atividade, o caráter instrucional, tecnicista e sistematizado dos materiais didáticos, o uso recorrente de ordens de execução, a manutenção de métodos, linguagem e recursos para a execução das atividades pertinentes a prática da modelagem e mesmo a constância de modelos do vestuário e concepções estéticas ao longo dos anos (saia lápis, vestido com recorte princesa e assim por diante). Essas características, acrescidas do enrijecimento das práticas de ensino, emolduram algumas das limitações vislumbradas ao longo das pesquisas e dificultam a abordagem do tema na perspectiva do sensível.

Pondera-se, contudo, que enquanto área de pesquisa, e mesmo em relação à sua presença no âmbito de cursos superiores, a modelagem está em processo de amadurecimento, assim como acontece com o dinâmico campo da Moda. Como apontado, o primeiro curso superior brasileiro exclusivamente voltado para o estudo da modelagem iniciou apenas em 1999. Mesmo em se tratando da presença anterior a esta data nas grades curriculares de cursos de Moda ou Design de Moda, acredita-se que a maturação da modelagem ainda esteja em processo de desenvolvimento.

Em relação às reflexões provenientes da prática docente, bem como das inquietações para com a abordagem do ensino de modelagem, acredita-se que são trajetos possíveis para uma aproximação deste com o campo do sensível. Promover práticas que insiram o estudante no centro do processo de aprendizagem, ou da ensinagem, estimular a reflexão e a construção de momentos de experimentação estética seriam, portanto, importantes balizadores do processo de construção do conhecimento por 
outro viés pedagógico.

Em se tratando do contexto de cursos superiores com o compromisso na promoção da criatividade e da inovação, acredita-se que as estratégias apresentadas possam ampliar as possibilidades de aplicação da modelagem para além da concepção de um mero recurso técnico desvinculado de um pensamento crítico e das etapas criativas. Assim, apesar de reconhecer a importância das técnicas e procedimentos da atividade de modelagem em ambiente industrial, defende-se, neste trabalho, o uso de meios de sensibilização dos estudantes para o corpo e a diversidade de olhares sobre sua relação com o vestir.

Por fim, salienta-se que as considerações aqui apresentadas surgiram das inquietações e da intenção de aprimoramento do fazer docente das pesquisadoras em direção a uma prática pelo e para o sensível, que seja significativa, pautada na construção dialógica do conhecimento e comprometida com a formação profissional e cidadã. Portanto, surgem, antes de tudo, da própria reflexão do ser/ estar no mundo das pesquisadoras, assim como da afirmação de um ensino possível tanto quanto almejado ${ }^{8}$.

\section{REFERÊNCIAS}

ARAÚJO, Ulisses F. Temas transversais, pedagogia de projetos e mudanças na educação. São Paulo: Summus, 2014.

ARAÚJO, Ulisses F.; SASTRE, Genoveva (orgs). Aprendizagem baseada em problemas. 3a Ed.São Paulo: Summus, 2016.

ARENHARDT, Simone; CARGNIN, Elisane Scapin; GERHARDT, Márcia Lenir; PEGORARO, E. S. C.; CARGNIN, Edileine S; LORENZONI, R. L. A formação do professor para uma educação do sensível na multiculturalidade. In: II Seminário Nacional de filosofia e Educação - confluências, 2006, Santa Maria, RS. Disponível em: http://coral. ufsm.br/gpforma/2senafe/PDF/025e3.pdf. Acesso em 05 jan. 2019.

BELSCHANSKY, Daniela Nunes Figueira. Modelagem: profissão e método. 2011. Dissertação (Mestrado em Moda, Cultura e Arte) - SENAC, São Paulo, 2011.

BEDUSCHI, Danielle Paganini. Diretrizes para o ensino de modelagem do vestuário. 2013. Dissertação (Mestrado Ciências) - Programa de Pós-Graduação em Têxtil e Moda. Escola de Artes, Ciências e Humanidades, Universidade de São Paulo, São Paulo, SP, 2013.

BRANDÃO, Gil. Aprenda a costurar. 3. ed. Rio de Janeiro: Edições Jornal do Brasil,

\footnotetext{
8 ADRIANO MAFRA. Doutor em Estudos da Tradução pela Universidade Federal de Santa Catarina (UFSC, 2015). Doutor em Translation Science pela Universiteit Antwerpen (2015). Mestre em Estudos da Tradução pela Universidade Federal de Santa Catarina (UFSC,2010). Especialista em Metodologia do Ensino de Linguas: Português, Inglês e Espanhol - Celer Faculdades (FACISA-2008). Graduado em Letras pela Universidade do Vale do Itajaí (UNIVALI, 2005). Email: adriano.mafra@ifc.edu.br
} 
DUARTE, Sônia; SAGGESE, Sylvia. Modelagem Industrial Brasileira. 5. ed. Rio de Janeiro: Guarda Roupa, 2010.

EMÍDIO, Lucimar de Fátima Bilmaia. Modelo MODThink: o pensamento de design aplicado ao ensino-aprendizagem e desenvolvimento de competências cognitivas em modelagem do vestuário. 2018. Tese (Doutorado Design) - Programa de Pós-graduação em Design, Faculdade de Arquitetura, Artes e Comunicação, Universidade Estadual Paulista, Bauru, 2018.

ESMOD, site oficial. History: the world's first and oldest fashion design school with exclusive and patended methods, 2016. Disponível em: http://www.esmod.com/en/ content/history. Acesso em 18 jan. 2019.

FARINA, Cynthia. Políticas do sensível no corpo docente: Arte e Filosofia na Formação Continuada de professores. Revista Thema, v.7, n.1. Instituto Federal de Educação, Ciências e Tecnologia Sul-rio-grandense. Pelotas, RS. 2010.

IERVOLINO, Fernanda. 41 anos de estudo de modelagem do vestuário: uma proposta de aperfeiçoamento do ensino de modelagem através da usabilidade. 2014. Dissertação (Mestrado Design) - Programa de Pós-graduação em Design, Universidade do Estado de Santa Catarina, Florianópolis -SC, 2014.

JUM NAKAO, site oficial. Workshop Metodologia Jum Nakao Modelar: Módulo 1. 2019. Disponível em: http://www.jumnakao.com/cursos/. Acesso em: 20 jan. 2019. LAVER, James. A roupa e a moda: uma história concisa. São Paulo: Companhia das Letras, 2005.

MORIN, Edgar. Educar na era planetária: o pensamento complexo como método de aprendizagem no erro e na incerteza humana. 2. Ed. São Paulo: Cortez; Brasília, DF: UNESCO, 2007.

. Os Sete Saberes Necessários à Educação do Futuro. 10.ed. São Paulo:

Cortez; Brasília, DF: UNESCO, 2005.

PASSOS, Ohana Gabi Marçal dos. As corporações de ofício nas sociedades medieval e industrial: uma análise comparativa entre os tecelões de Gerhart Hauptmann e o alfaiate dos irmãos Grimm. 2016. Dissertação (Mestrado História Comparada) - Universidade Federal do Rio de Janeiro, Instituto de História, Programa de Pós-Graduação em História Comparada, Rio de Janeiro, 2016.

PÁTARO, Ricardo Fernandes. $O$ trabalho com projetos na escola: um estudo a partir de teorias de complexidade, interdisciplinaridade e transversalidade. 2008. Dissertação (Mestrado Educação) - Programa de Pós-graduação em Educação, Universidade Estadual de Campinas, Campinas-SP, 2008. 
PIMENTA, Selma G.; ANASTASIOU, Léa das graças C. Docência no Ensino Superior. 5ำ Ed. São Paulo: Cortez, 2014.

RIFFEL, Renato; A reformulação das atividades de alfaiataria na região do Vale do Itajaí-Mirim diante do surgimento do mercado de "pronto-para-vestir" na década de 1970. 2003. Monografia (Especialização em Moda) - Centro de Artes, Universidade do Estado de Santa Catarina, Florianópolis, 2003.

SILVEIRA, Icléia; SILVA, Giorgio. Conhecimentos dos modelistas catarinenses e os softwares utilizados nos setores de modelagem do vestuário. Moda palavra e-periódico, Florianópolis, ano 4, n.7, jan./jun. 2011. Disponível em: http://www.revistas. udesc.br/index. php/modapalavra/article/view/7909. Acesso em: 15 jan. 2019.

UDESC. Apostila de Modelagem Infantil e Masculina. UDESC/CEART, 2017. Disponível em: https://www.udesc.br/arquivos/ceart/id_cpmenu/3787/Apostila_MODELAGEM_Infantil_e_Masculina___2017_15206211782774_3787.pdf. Acesso em: 18 jan. 2019.

UDESC. Apostila de Modelagem Básica do Vestuário Feminino. UDESC/CEART, 2017.Disponível em: https://www.udesc.br/arquivos/ceart/id_cpmenu/3787/Apostila_Modelagem_B_sica_Feminina___2017_15206211994746_3787.pdf. Acesso em: 18 jan. 2019.

UDESC. Apostila de Modelagem Avançada Feminina. UDESC/CEART, 2017.Disponível em: https://www.udesc.br/arquivos/ceart/id_cpmenu/3787/Apostila_Modelagem_Avan_ada___2017_15206212782182_3787.pdf. Acesso em: 18 jan. 2019.

UNIVERSIDADE do Estado de Santa Catarina. Reforma Curricular do Curso de Bacharelado em Moda. Centro de Artes, Departamento de Moda. Florianópolis, 2016. Disponível em: https://www.udesc.br/arquivos/ceart/id_cpmenu/325/ Bacherelado_Moda_2016_2_-_Aprovado_CONSEPE_-_CONSADE__CONSUNE_14997940118182_325.pdf. Acesso em: 17 jan. 2019.

Recebido em: 02/03/2020

Aceito em: 08/04/2020 